Jpn. J. Pharm. Health Care Sci.

\title{
Usefulness of Questions from Patients and Their Families in Medication Guidance - Role of the Pharmacist in Integrated Therapy for Blood Cancer-
}

\author{
Akihiro Okuno ${ }^{* 1}$, Kouichi Hosomi ${ }^{1}$, Megumi Maekawa ${ }^{1}$, Yoshiharu Umetani', \\ Yasuo Tsuda ${ }^{1}$, Shinsaku Ohnishi ${ }^{1}$, Teruhisa Araya ${ }^{1}$, Kinya Yamamoto ${ }^{3}$, \\ Shizuo Takamiya ${ }^{3}$, Michiaki Sato ${ }^{3}$ and Kenji Matsuyama ${ }^{4}$ \\ Department of Pharmacy, Nishi-Kobe Medical Center ${ }^{1}$ \\ Department of Pharmacy, Kobe West City Hospital ${ }^{2}$ \\ Department of Psychiatry, Nishi-Kobe Medical Center ${ }^{3}$ \\ Department of Clinical Pharmacy, Faculty of Pharmaceutical Sciences, \\ Mukogawa Women's University ${ }^{4}$ \\ $\left[\begin{array}{l}\text { Received March 9, } 2004 \\ \text { Accepted August 1, 2004 }\end{array}\right]$
}

This report describes how good medication guidance may be provided to patients with blood cancer and discusses the role of the pharmacist in raising the satisfaction of patients and family members with treatment. Chemotherapy for blood cancer causes a variety of severe adverse reactions, giving patients and their families a feeling of anxiety towards it. It is therefore necessary for pharmacists to provide medication guidance in order to reduce anxiety towards drugs during longterm chemotherapy.

In the present study, we examined questions regarding chemotherapy from patients and their families for 32 cases in the past 3 years. The 485 questions asked were classified according to subject as follows : 1) Adverse reactions- $40 \%, 2$ ) Chemotherapy protocol-12\%, 3) Blood transfusions-7\%, 4) Effects of chemotherapy-6\%, 5) Granulocyte-colony stimulating factor (G-CSF)-6\%, 6) Method of use-4\%, 7) Drugs preventing opportunistic infections-4\%, 8) Administration method- 3 $\%, 9)$ Chemotherapy in outpatient ward-3\%, 10) High-dose chemotherapy-3\%, 11) Discharge and short stay at home-1\%, 12) Drop-out- $1 \%, 13)$ Drawing blood- $1 \%, 14)$ Color of chemotherapy agents for injection-1\%, and 15) Differences between treatment strategies at other hospitals- $1 \%$.

Key words — medication guidance, blood cancer, chemotherapy, anxiety, integrated therapy

\section{Introduction}

Currently, cancer chemotherapy is performed under various protocols including combination chemotherapy and high-dose chemotherapy, resulting in a remarkable improvement in cure rate ${ }^{1)}$.

In the case of leukemia, even if symptoms due to the primary disease are improved when complete remission is achieved by induction chemotherapy, the patients may begin to suffer from adverse reactions, such as bone marrow depression, various infections, alopecia, stomatitis, nausea, and vomiting ${ }^{2)}$. These adverse reactions cause patients and their families to experience various levels of anxiety.

In this regard, it is necessary to examine how adequate patient instruction by a pharmacist can reduce chemotherapy anxiety and helps to assure the patients and their families.
We focused on a variety of anxieties, complaints and questions obtained from patients and their families during chemotherapy, and then discussing them in terms of the role of pharmacists in the integrated treatment of blood cancer.

Integrated treatment by medical staff at Nishi-Kobe Medical Center

Pharmacists and other medical staff at Nishi-Kobe Medical Center supported patients and their families through appropriate medication guidance that reduced their anxiety about drugs ${ }^{3-5)}$.

The members in integrated treatment consisted of physicians, pharmacists, nutritionists, psychiatrists, psychologist, nurses, and so on. The role of each staff member in medication guidance is summarized in Table 1.

Physicians played a leading role in medical care, together with reducing patient anxiety through daily rounds of the patients. 
Table 1. Role of Each Staff Member in Medication Guidance at Nishi-Kobe Medical Center.

\begin{tabular}{|c|c|}
\hline Physician & $\begin{array}{l}\text { To play a leading role in medical care } \\
\text { To reduce patient anxiety through daily rounds of } \\
\text { the patients }\end{array}$ \\
\hline Pharmacist & $\begin{array}{l}\text { To the effects of the drugs, as well as potential } \\
\text { adverse reactions, } \\
\text { To explain the most suitable method of drug } \\
\text { administration } \\
\text { To provide medication guidance with regards to } \\
\text { patient and family anxiety }\end{array}$ \\
\hline Nutritionist & $\begin{array}{l}\text { To provide nutrition guidance and encouraged } \\
\text { patients to improve meal menus to reduce anorexia } \\
\text { resulting from adverse reaction to the drugs }\end{array}$ \\
\hline Psychiatrist & $\begin{array}{l}\text { To support the mental care of the patients as well as } \\
\text { their families through daily rounds of the patients } \\
\text { To provide counseling to the patients and their } \\
\text { families } \\
\text { To advise the medical staff to promote } \\
\text { understanding of the actions or words of the } \\
\text { patients }\end{array}$ \\
\hline Psychologist & $\begin{array}{l}\text { To provide psychological care to the patients and } \\
\text { their families to reduce mental stress }\end{array}$ \\
\hline Nurse & $\begin{array}{l}\text { To provide total nursing care to patients and their } \\
\text { families, including mental health care } \\
\text { To coordinate patients, families and medical staff } \\
\text { To assure quality of life (QOL) during } \\
\text { hospitalization }\end{array}$ \\
\hline
\end{tabular}

Pharmacists played an important role in pharmaceutical care by explaining the effects of the drugs, potential adverse reactions, and the most suitable method of drug administration in order to reduce patient and family anxiety.

Nutritionists provided nutrition guidance and encouraged patients to improve meal menus to reduce anorexia resulting from adverse reaction to the drugs. During the chemotherapy term, nutritionists explained the reason why raw foods were prohibited after pharmacists explained bone marrow depression caused by chemotherapeutic agents.

Psychiatrists supported the mental care of the patients as well as their families through daily rounds of the patients and providing counseling to the patients and their families. They advised pharmacists to promote understanding of the actions or words of the patients.

Psychologists provided psychological care to the patients and their families to reduce mental stress. Psychologists could grasp the most effective time for psychological care after discussion with pharmacists regarding the times when the adverse reactions of chemotherapeutic agents would occur most severely.

Nurses provided total nursing care to patients and their families, including mental health care, coordinate patients, families and medical staff and assure quality of life (QOL) during hospitalization. Nurses and pharmacists cooperated to avoid noncompliance with drug therapy.

\section{Subjects}

The subjects of this study included 32 patients (16 males and 16 females) admitted between September 1998 and August 2001 with the diagnosis of blood cancer. There were 5 patients treated in the pediatric department and 27 in the internal department of immunohematology. Patients ages ranged from 4 years old to 87 years old (mean 48.7 years old). The mean hospitalization period was 96 days. During the hospitalization period, medication guidance was provided an average of 19.5 times. The number of patients with malignant lymphoma, acute myelocytic leukemia, acute lymphatic leukemia and multiple myeloma were 16, 11, 4 and 1, respectively. Table 2 shows a list of chemotherapeutic agents administered to 32 patients.

\section{Methods}

Initially, the physician explained the present chemotherapy to the patients and their families. Thereafter, a pharmacist regularly attended the bedside $1-3$ times per week to provide medication guidance. Anxieties, complaints and questions about chemotherapy were obtained from the patients and their families during medication guidance. 
Table 2. Chemotherapeutic Agents Administered to 32 Patients.

\begin{tabular}{|l|c|}
\hline \multicolumn{1}{|c|}{ Chemotherapuetic agents } & Number of cases \\
\hline Cytarabine & 21 \\
\hline (High-dose chemotherapy) & $(3)$ \\
\hline Cyclophosphamide & 20 \\
\hline (Peripheral blood stem cell transplantation) & $(1)$ \\
\hline Etposide & 19 \\
\hline Vincristine & 17 \\
\hline Methotrexate & 12 \\
\hline (High-dose chemotherapy) & $(3)$ \\
\hline (Peripheral blood stem cell transplantation) & $(1)$ \\
\hline Daunorubicin & 11 \\
\hline Idarubicin & 9 \\
\hline Pirarubicin & 8 \\
\hline Enocitabine & 8 \\
\hline Doxorubicin & 7 \\
\hline Aclarubicin & 5 \\
\hline L-asparaginase & 4 \\
\hline Mitoxatrone & 4 \\
\hline Carboplatin & 4 \\
\hline Mercaptopurine & 2 \\
\hline Bleomycin & 2 \\
\hline Dacarbazine & 2 \\
\hline Vindesine & 2 \\
\hline Hydroxycarbamide & 2 \\
\hline Tretinoin & 2 \\
\hline Melphalan & 2 \\
\hline (Peripheral blood stem cell transplantation) & $(1)$ \\
\hline Vinblastine & 1 \\
\hline Procarbazine & 1 \\
\hline Ubenimex & 1 \\
\hline Ranimustine & 1 \\
\hline Fluorouracil & 1 \\
\hline Actinomycin D & 1 \\
\hline & \\
\hline & 2 \\
\hline
\end{tabular}

\section{Results and Discussion}

\section{Classification of anxieties, complaints and questions} about chemotherapy from patients and their families

The anxieties, complaints and questions about chemotherapy are summarized in Fig. 1. There was a total of 485 questions. Among these, there were 194 questions about adverse reactions(40\%), 57 questions about chemotherapy protocol (12\%), 33 questions about blood transfusions (7\%), 28 questions about the effects of chemotherapy (6\%), and other questions. The details of the anxieties, complaints and questions are shown in Table 3. There were some questions that were difficult for patients and their families to ask their doctor, or that they had already asked but wanted to ask the pharmacist to obtain a second opinion.

There was no relation among questions from patients and their treatment times. Among various chemotherapeutic agents, there were no obvious differences in the contents of questions.

Questions related to adverse reactions accounted for the largest percentage of the questions, $40 \%$, suggesting the necessity of supportive care from pharmacists. It is of special interest that non-physical aspects other than adverse reactions were accounted for $(60 \%)$. Coates et al. asked patients to identify and rank the side effects of their cancer chemotherapy $^{6}$. The incidence of non-physical side effects was 54 $\%$, which is in good accordance with our present research. These common results suggest further consideration of these factors.

Classification of the questions regarding adverse reactions

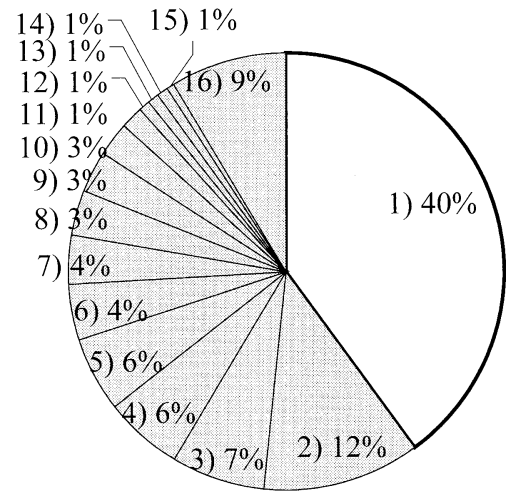

Fig. 1. Classification of Anxieties, Complaints and Questions about Chemotherapy from Patients and their Families.

1) Adverse reactions (194) $40 \%$, 2) Chemotherapy protocol $(57) 12 \%, 3)$ Blood transfusions (33) 7\%, 4) Effects of chemotherapy (28) $6 \%, 5)$ Granulocyte-colony stimulating factor (28) 6\%, 6) Usage method (20) 4\%, 7) Drugs preventing opportunistic infections (17) $4 \%, 8$ ) Administration method (16) 3\%, 9) Chemotherapy at the outpatient ward (15) 3\%, 10) Highdose chemotherapy $(13) 3 \%, 11)$ Discharge and short stay at home (7) $1 \%$, 12) Drop-out (5) 1 $\%$, 13) Drawing blood (4) $1 \%, 14$ ) Color of chemotherapeutic agents for injection (3) $1 \%$, 15) Differences in the treatment strategies at other hospitals (3) $1 \%, 16$ ) Others (42) $9 \%$. There were 485 questions.

is summarized in Fig. 2. Among 194 questions regarding adverse reactions, the main questions were related to decreased WBC [white blood cell] (43 questions), and opportunistic infections (36 questions). The rest were as follows : alopecia (23 questions), drug allergies (12 questions), stomatitis (9 questions), adverse reactions due to drugs other than chemotherapeutic agents (8 questions), and so on.

\section{Examples of medication guidance}

Typical medication guidance between patients and pharmacists is described below as Examples 1 through 9.

Example $1: 1)$ Adverse reactions [Decreased WBC]

A patient undergoing chemotherapy for the first time said, "Why do I get fatigued when WBC counts decrease ? I' m afraid of becoming bedridden."

Medication guidance : 1) If you take care of preventing infections by hygienic conditions, you will not always develop infections when WBC is decreased. 2) Keeping yourself clean prevents you from getting fatigued and becoming bedridden. In response, the patient said, "I will prevent infections carefully."

As shown in Example 1, patients feel anxiety about the decrease in WBC counts. However, detailed medication guidance regarding WBC helped the patients overcome their anxiety about decreased WBC counts, which led patients to a more positive attitude while undergoing the severe chemo- 
Table 3. Contents of Anxieties, Complaints and Questions.

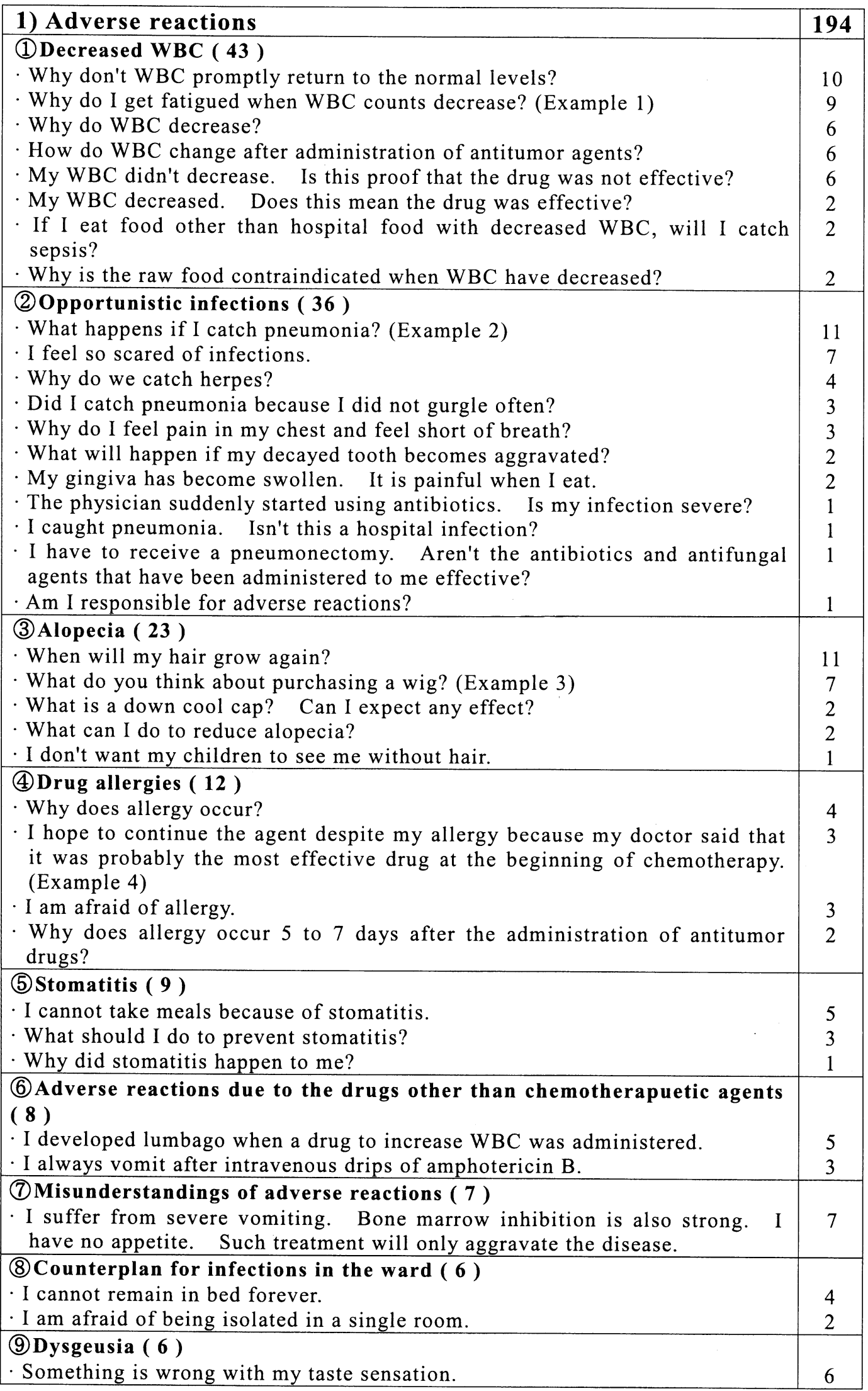




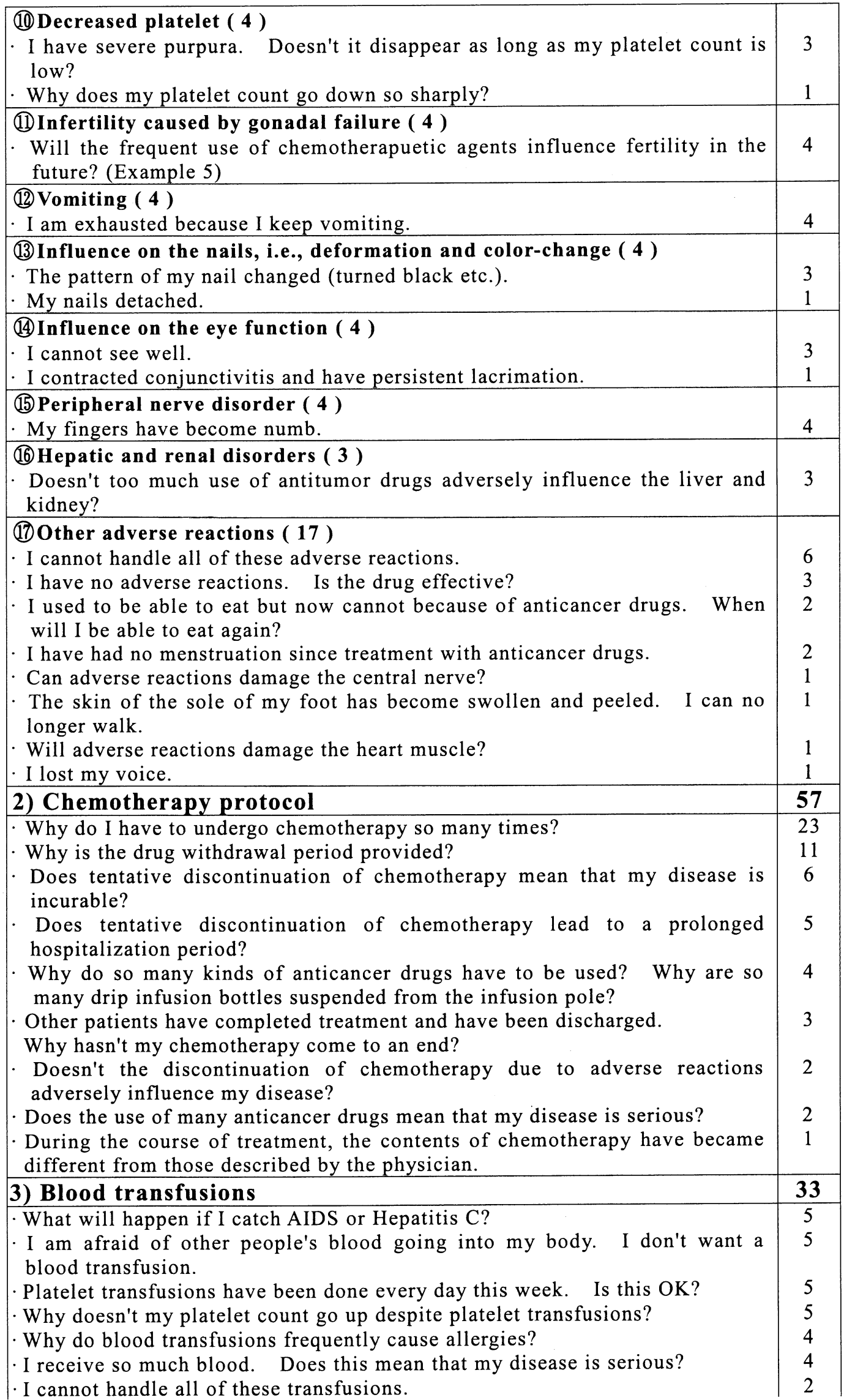


- If I catch AIDS, don't I get my family into trouble?

I have anemia. Why don't I get blood transfusion? Doesn't anemia require transfusion?

\begin{tabular}{l}
\hline 4) Effects of chemotherapy \\
\hline - Is chemotherapy really effective? \\
. Will chemotherapy cure me completely? (Example 6) \\
Will my physician make a solemn promise of a complete cure from the \\
present chemotherapy? (Example 6) \\
- Are the previous drugs ineffective for recurrence? \\
My doctor said that the previous drugs were ineffective. Are the next \\
drugs effective? \\
Why is it that the same drug at the same dose was given to me and other \\
patients who had the same disease but it was not effective for me alone? \\
\hline Do I have to go through more chemotherapy if the disease recurrs?
\end{tabular}

\begin{tabular}{|l|l|}
\hline 5) Granulocyte-colony stimulating factor & $\mathbf{2 8}$ \\
\hline
\end{tabular}

\begin{tabular}{|l|l}
\hline - If a drug to increase WBC is used, how does the leukocyte count fluctuate? & 10
\end{tabular}

Isn't it possible to use a drug to increase WBC before chemotherapy?

Why doesn't the leukocyte count go up despite the use of a drug to increase WBC?

Why does the effect of a drug to increase WBC decrease if it is repeatedly used many times?

The leukocyte count went up excessively after the use of a drug to increase WBC.

Doesn't my disease become aggravated if a drug to increase WBC is used?

Isn't it possible to increase the dose of a drug to increase WBC?

Is it no problem to use a drug to increase WBC repeatedly?

6) Usage method

How should I gurgle? (For how many seconds? How should I gurgle 18 when I have severe nausea? Many types of gurgles are prescribed. In what order, should I use them?)

What can I add to amphotericin syrup to make its taste better?

How should I use oblate?

How should I fill the powder drug in a capsule?

I always choke when I inhale amphotericin. What is the best way of 1 inhaling it?

7) Drugs preventing opportunistic infections

- Too many types of drugs are prescribed. I cannot take all of them.

I don't want inhalation.

Do I get infections at once if I stop gurgling and inhalation?

I hate gurgling.

- I don't want to take these drugs.

8) Administration method

- What is intraspinal injection? Why is the drug injected into the hips?

Why is the drug injected into the vessel below the shoulder (superior vena cava)?

Why does my headache persist for 2 weeks after intraspinal injection into hips?

What is intramuscular injection? Why is the drug injected into my bottom?

Why can't the drip infusion, intramuscular injection and intraspinal injection of anticancer drugs be conducted on the same day?

- Why was it necessary to implant a reservoir?

9) Chemotherapy at the outpatient ward 28

What precautions are necessary for continuing chemotherapy at the 15 outpatient ward? (Example 7)

Is massive chemotherapy also used at the outpatient ward?

Why is treatment given at the outpatient ward? What should I do if my condition gets worse at home? 


\begin{tabular}{|c|c|}
\hline 10) High-dose chemotherapy & 13 \\
\hline Do adverse reactions increase in proportion to the increase in dose? & 7 \\
\hline Do patients sometimes die due to severe adverse reactions? & 4 \\
\hline - Does high-dose chemotherapy mean that my disease is severe? & 2 \\
\hline 11) Discharge and short stay at home & 7 \\
\hline $\begin{array}{l}\text { I do not want to be discharged from the hospital until I am completely cured } \\
\text { by chemotherapy. (Example } 8 \text { ) }\end{array}$ & 5 \\
\hline $\begin{array}{l}\text { I do not want a short stay at home until the scheduled chemotherapy is } \\
\text { completed. (Example } 8 \text { ) }\end{array}$ & 2 \\
\hline 12) Drop-out & 5 \\
\hline $\begin{array}{l}\text { What will happen if I s } \\
\text { I want to keep working }\end{array}$ & $\begin{array}{l}4 \\
1\end{array}$ \\
\hline 13) Drawing blood & 4 \\
\hline $\begin{array}{l}\text { even though I am receiving blood transfusions? } \\
\text { d? }\end{array}$ & $\begin{array}{l}2 \\
1\end{array}$ \\
\hline - Why do you have to take my blood so often? & $\frac{1}{2}$ \\
\hline 14) Color of chemotherapeutic agents for injection & 3 \\
\hline $\begin{array}{l}\text { After drip infusion of red anticancer drugs, my urine immediately turned } \\
\text { red. Didn't the anticancer drug simply pass through my body without } \\
\text { being absorbed? }\end{array}$ & 2 \\
\hline $\begin{array}{l}\text { I am scared of blue antitumor drugs. } \\
\text { 15) Differences in the treatment strategies at other hospitals }\end{array}$ & $\frac{1}{3}$ \\
\hline $\begin{array}{l}\text { Why are drugs for opportunistic infections different from those given at } \\
\text { other hospitals? }\end{array}$ & 2 \\
\hline $\begin{array}{l}\text { Why is the timing of antibiotic administration different from that performed } \\
\text { at other hospitals? }\end{array}$ & 1 \\
\hline 16) Others & 42 \\
\hline $\begin{array}{l}\text { Are there many patients who are receiving similar chemotherapy? } \\
\text { (Example 9) }\end{array}$ & 10 \\
\hline $\begin{array}{l}\text { Sometimes the explanation given by the physician and the medical care } \\
\text { given by the nurse are different. Is this OK? }\end{array}$ & 7 \\
\hline $\begin{array}{l}\text { A celebrity who had the same disease died. Did drug therapy fail in that } \\
\text { patient? }\end{array}$ & 6 \\
\hline Are better drugs expected in the future? & 5 \\
\hline $\begin{array}{l}\text { Everybody tells me to "hold on!" during chemotherapy. How should I hold } \\
\text { on? }\end{array}$ & 4 \\
\hline $\begin{array}{l}\text { Sometimes the medical care given is different between the nurses even } \\
\text { though their jobs are the same. }\end{array}$ & 3 \\
\hline $\begin{array}{l}\text { Due to the decrease in platelet, my menstruation was stopped by a drug. } \\
\text { Does this return to the original state after completion of treatment? }\end{array}$ & 3 \\
\hline Why is it necessary to promote urination so much? & 2 \\
\hline apparatus makes me so afraid that I tremble all & 2 \\
\hline
\end{tabular}

therapy.

Example 2:1) Adverse reactions [Opportunistic infections]

A patient with a prolonged persistent decrease in leukocytes said "I' $m$ afraid of catching pneumonia if I do nothing for my decreased leukocytes. What happens if I catch pneumonia?"

Medication guidance: 1) Antibiotics have already been prescribed, which reduces the risk. Even if you catch pneumonia, the symptoms will be less severe compared with that in patients who are not being given these drugs. 2) Regular gurgling and hand washing can effectively reduce the risk.
In response, the patient said, "I shall do everything to prevent infections more carefully."

As shown in Example 2, patients feel severe anxiety regarding opportunistic infections. When they became aware of the importance of cooperation between patients and staff, they were able to overcome their anxiety about pneumonia. The most important point for medication guidance is to sympathize with the patient and promote a strong will to overcome the blood cancer.

Example $3: 1)$ Adverse reactions [Alopecia]

The 7 questions regarding "purchasing a wig" were asked by women. All patients said, "What do you think about pur- 


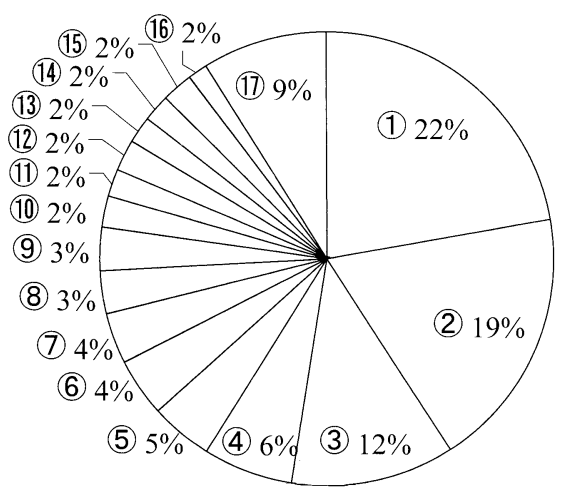

Fig.2. Classification of the Questions Regarding Adverse Reactions.

(1)Decreased WBC (43) 22\%, (2)Opportunistic infections (36) 19\%, (3)Alopecia (23) 12\%, (4) Drug allergies (12) 6\%, 5) Stomatitis (9) $5 \%$, (6) Adverse reactions due to the drugs other than chemotherapeutic agents (8) 4\%, (7)Misunderstanding of adverse reactions (7) 4\%, 8Counterplan for infections in the ward (6) $3 \%$, (9) Dysgeusia (6) $3 \%$, (10)Decreased platelet (4) 2 $\%$, (11)Infertility caused by gonadal failure (4) 2 $\%$, (12) Vomiting (4) $2 \%$, (13)Influence on the nails, i.e., deformation and color-change (4) 2 $\%$, (14)Influence on the eye function (4) $2 \%$, (15) Peripheral nerve disorder (4) $2 \%$, (16) Hepatic and renal disorders (3) $2 \%$, (17) Other adverse reactions (17) $9 \%$.

chasing a wig ? I don't want to purchase a wig, because it conceals the real'me', and it does not directly relate to cancer treatment."

Medication guidance : 1) If you wear a wig when you go out or stay overnight at home, you may create time when you can forget about the disease. 2) A wig is not merely a means of hiding alopecia from others, but can also be an effective means of diversion. 3) Diversion is an important factor in overcoming painful, long-term chemotherapy. In response, the patients said, "I shall wear a wig for a diversion." "If I wear a wig, my family may be able to change their mood." As a result, all patients voluntarily purchased wigs.

In Example 3, it is interesting that the patients did not want to purchase a wig until they were ready to accept alopecia. The problem of appearance is important, especially for female patients undergoing cancer chemotherapy, and is reflected in the number of questions (23 questions) regarding alopecia. The pharmacist should try to understand the complex uncertainties of the patient about buying a wig, and inform them that a wig is an important tool for diversion, which may enable them to overcome severe chemotherapy. Subsequently, the patients were convinced of the necessity of a wig and all bought one. Their anxieties about alopecia were overcome by purchasing wigs.

Example 4:1) Adverse reactions [Drug allergies]

Drug allergies are sometimes found in patients undergoing cancer chemotherapy. A patient who had to discontinue a drug because of allergy said, "I hope to continue the agent despite my allergy because my doctor said that it was probably the most effective drug at the beginning of chemotherapy. I'm afraid of what will happen if the agent is discontinued."

Medication guidance : 1) The allergy-reaction is sometimes so serious that we must decide to stop the administered chemotherapeutic agents even if they are the most effective ones. 2) It is important for us to respond to allergic signs and apply alternative chemotherapy. 3) The reason why pharmacists and other medical staff visit your bedside so frequently is to interpret the signs. In response, the patient said, "I understand that choosing proper chemotherapy without allergic reaction is more important than the most effective one."

In Example 4, when chemotherapy was suddenly discontinued because of allergic reaction, the patients felt anxiety because they had anticipated positive effects from the chemotherapeutic agent. The pharmacist advised them that the drug allergy was an important sign for reconsideration of chemotherapy, and told the patient that all of the medical staff would support them. As a result, they were able to accept the sudden discontinuation of drug therapy.

Example 5:1) Adverse reactions [Infertility caused by gonadal failure]

Young patients and mothers of young female patients felt anxiety as to whether the administered chemotherapeutic agents would influence fertility. Representative questions are as follows, "Will the frequent use of chemotherapeutic agents influence fertility in the future?" Have young women who completed cancer chemotherapy given birth ?" "If I become pregnant, who should I consult?"

Medication guidance : 1) At present, the data are not sufficient to predict the possibility of pregnancy in the future. 2) There are a few instances where chemotherapy has influenced pregnancy, but there are many women who have had healthy babies after treatment. 3) It is important to consult a physician when judging the best time to become pregnant. 4) The most important thing is to complete the current chemotherapy. The pharmacist advised the patient that the risk of infertility is close to that of women who had not been given chemotherapeutic agents. In response, these patients said, "When we want to become pregnant after completion of the treatment, we shall consult the staff."

As shown in the questions above, anxiety about infertility is a serious issue for young patients. Intensive chemotherapy cannot start until resolution of the anxiety is achieved. Sufficient explanation by the pharmacist and other medical staff members helps young patients overcome anxiety about infertility while undergoing several courses of chemotherapy.

Example 6:4) Effects of chemotherapy

Patients undergoing long-term chemotherapy tended to ask the following questions. They asked, "Will chemotherapy cure me completely?" "Will my physician make a solemn promise of a complete cure from the present chemo- 
therapy? " I do not understand why I am not cured because I have already endured a long stay in the hospital."

Medication guidance : 1) The long-term objective of chemotherapy is to restore your body as it was before. 2) However, the first objective of this therapy is to achieve complete remission. Under the remission state, the disease is not completely cured but suppressed, making it possible for patients to undergo chemotherapy at an outpatient ward. In response, the patient said, "I understand the meaning of remission."

In Example 6, it is natural that the patients wish to return to their former status in compensation for enduring the chemotherapy. At the time of medication guidance, the pharmacist should listen to the natural feelings of the patients, and follow with an empathic response. Afterward, the pharmacist must explain the concept of remission achieved by chemotherapy, which moves patients from hospital chemotherapy to that in an outpatient ward.

Example $7: 9$ ) Chemotherapy at the outpatient ward

When leaving the hospital, the patients and families said, "What precautions are necessary for continuing chemotherapy at the outpatient ward?" They added, "What about catching possible infections in the waiting room for outpatients?" "What should be done if a family member catches a cold?" "What cautions are necessary regarding food?" They also asked whether they could participate in school outings such as sports events or going to a zoo.

Medication guidance : Detailed instructions were given for each question. When it was difficult for the pharmacist to answer immediately, the pharmacist asked the other medical staff to answer for them.

In general, the patients and families felt anxiety towards the change in environment from the hospital to the home. Patients undergoing cancer chemotherapy may develop various types of infections. They are especially nervous of every kind of infection in a new environment other than the hospital. As shown in Table 1, integrated treatment including other medical staff members becomes essential for medication guidance.

Example 8 : 11) Discharge and short stay at home

In general, patients undergoing chemotherapy tend to feel anxious about discharge from the hospital after the achievement of remission. Change to chemotherapy at the outpatient ward often results in several patient complaints about the decision. They said, "I do not want to be discharged from the hospital until I am completely cured by chemotherapy." II do not want a short stay at home until the scheduled chemotherapy is completed."

Medication guidance : 1) It is better to think that chemotherapy for blood cancer is conducted not only at the hospital but also at the outpatient ward. 2) After achieving remission, the chemotherapy at outpatient ward is a very important process in achieving a complete cure. 3) The psychological stress caused by long-term hospitalization sometimes obstructs the continuation of chemotherapy and causes a delay in rehabilitation. 4) Chemotherapy at an outpatient ward changes the mental state, increasing the will to overcome the disease, which is an important factor in enduring adverse reactions and in continuing chemotherapy.

During guidance, it was clarified that the patients were afraid of changing from the hospital to the outpatient ward because they thought that discontinuance of chemotherapy at the hospital meant giving up the present chemotherapy.

Regarding the misunderstanding above, an accurate explanation of chemotherapy at the outpatient ward results in patient agreement to a short stay at home, resulting in discharge from hospital.

Example 9:16) Others [Loneliness caused by the interruption of social activities]

Patients who were isolated from other cancer patients often felt lonely because of a lack of communication with other patients. A representative question from such a patient follows. "Are there many patients who are receiving similar chemotherapy?" This is a question asked by one patient who was isolated in a private room and had therefore no means of communication with other patients.

Medication guidance: 1) There are many patients undergoing similar chemotherapy. 2) Many medical staff members in the integrated treatment carry out the present chemotherapy. 3) A pharmacist is also monitoring the patient's chemotherapy from perspective that is different from those of other medical staff members so that the optimal chemotherapy is conducted. In response, the patient said, "Thank the staff for me." "Please take care of me hereafter."

From Example 9, we can recognize how the cancer patient needs communication with other patients with the same disease as well as encouragement from the medical staff. To patients under medical treatment in a private room, the most effective encouragement is to tell them there are many patients undergoing similar painful chemotherapy regimens. Sympathizing with each other is thought to play an important role in overcoming blood cancer.

When a patient is diagnosed as having blood cancer and sent to the hospital, the anxiety may be beyond imagination. The patient who undergoes a series of painful cancer chemotherapies and clinical tests tends to develop some form of maladjustment, i.e., depression, emotional disturbances, and acute stress disorder. Their families must also accept the shock of the cancer diagnosis, the sensation of strong fear, and the feeling of helplessness. Post traumatic stress reaction (PTSR) is thought to occur not only in patients but also in their families ${ }^{7}$. The communication skills of the medical staff have an intense effect on the practice of patientcentered care ${ }^{8-10)}$. When a patient with blood cancer is under medical care in the hospital, integrated treatment by a team of physicians, psychiatrists, nurses and pharmacists is necessary. As shown in Table 1, Nishi-Kobe Medical Center has established an integrated treatment system for patients with blood cancer. Care for patients and families was improved so that pharmacists and other medical staff shared information about the patients with each other. Along with each staff member of the integrated treatment system, the pharma- 
cists at Nishi-Kobe Medical Center provide support for the patients and their families through appropriate medication guidance to reduce their anxiety about blood cancer chemotherapy.

The medication guidance by pharmacists was evaluated by doctors resulting in the increase in the monthly number of requests by doctors from 90 cases in 1998 to 147 cases in 2001.

As described in the Examples, listening and empathic responses from pharmacists enabled them to draw out the subconscious anxiety of the patients, promoting confidence in the relationship between the patients and the pharmacists. This relationship between the patients and the pharmacists helped the patients understand the side effects of chemotherapeutic agents and good compliance was achieved. The role of pharmacists in the integrated treatment system ensures high quality care. The role of pharmacists in the pharmacoeconomics of cancer chemotherapy and therapeutic effects is now under examination.

\section{References}

1) A.M. Evens, M.S. Tallman, "Handbook of Cancer Chemotherapy” 6 th ed., ed. by R.T. Skeel, Lippincott Williams \& Wilkins, Inc., Philadelphia, 2003, pp.411-459.

2) P.I. Folb, "Meyler's Side Effects of Drugs," 12 th ed., ed. by M. N. G. Dukes, Elsevier Science Publishers B. V., Amsterdam, 1992, pp.1107-1163.

3) A. Okuno, K. Hosomi, M. Maekawa, T. Sato, Y. Umetani, S. Tsuruta, Medicine and Drugs Journal, 36, 2844-2848 (2000).

4) A. Okuno, K. Hosomi, M. Maekawa, S. Takamiya, H.
Harigaya, Y. Umetani, T. Araya, N. Takase, The Role of the Pharmacist in Integrated Treatment for Pediatric Patients with Eating Disorder, Jpn. J. Psychosom. Med., 42, 449-458 (2002).

5) A. Okuno, K. Hosomi, M. Maekawa, Y. Umetani, T. Araya, K. Yamamoto, S. Takamiya, T. Sato, K. Matsubara, K. Baba, The Role of Pharmaceutical Care for the Parents with Children Receiving Chemotherapy for Leukemia: Through Pharmaceutical Care for Two Cases of Acute Lymphocytic Leukemia, JJSPP, 11, 35-40 (2002).

6) A. Coates, S. Abraham, S.B. Kaye, T. Sowerbutts, C. Frewin, R.M. Fox, M.H.N. Tattersall, On the Receiving End-Patient Perception of the Side-effects of Cancer Chemotherapy, Eur. J. Cancer Clin. Oncol., 19, 203208 (1983).

7) S. Takamiya, K. Matsubara, T. Kawamoto, K. Shirakawa, R. Ido, K. Sasai, M. Tsukioka, C. Yonenaga, A. Okuno, K. Hosomi, T. Okumura, M. Matsumoto, Y. Takahara, K. Yamamoto, T. Sato, B. Kunizo, Multidisciplinary Psychosocial Support for Pediatric Patients with Cancer and Their Families, Jpn. J. Psychosom. Med., 44, 51-59 (2004).

8) W.N. Tindall, R.S. Beardsley, C.L. Kimberlin,"Communication Skills in Pharmacy Practice: A Practical Guide for Students and Practitioners" 3 rd ed., Lippincott Williams \& Wilkins, Inc., Baltimore, 1994, pp.6585.

9) P. Maguire, Improving Communication with Cancer Patients, Eur. J. Cancer, 35, 2058-2065 (1999).

10) T. Greenhalgh, B. Hurwitz, Narrative based medicine: Why study narrative ?, BMJ, 318, 48-50 (1999). 